\title{
Using Composite Resin Inclined Plane for the Repositioning of a Laterally Luxated Primary Incisor: A Case Report
}

\author{
Volkan Arikan ${ }^{a}$
}

Saziye Saria

\section{ABSTRACT}

This case report describes the repositioning of a laterally luxated primary central incisor with occlusal interference, using a composite inclined plane. The patient was a 4-year-old girl who applied to our clinic three days after the injury. Because of the time delay between injury and presentation, it was not possible to reposition the tooth with pressure. Following a root-canal treatment, an inclined plane was prepared on the lower primary incisors, using composite resin. The tooth was repositioned in two weeks, and the inclined plane was then removed. After 1 year of follow-up, the treatment was found to be successful, both clinically and radiographically. The use of a composite inclined plane, accompanied by careful follow-up, is an effective alternative to extraction for laterally luxated primary incisors with occlusal interference. (Eur J Dent 2011;5:117-120)

Key words: Inclined plane; Primary teeth; Dental trauma.

\section{INTRODUCTION}

Primary teeth injuries are common in young children due to their lack of muscle coordination in the early years of life. ${ }^{1-4}$ These injuries primarily affect anterior primary teeth; as a result of the resilient bone surrounding the primary teeth, these injuries are usually luxations. , $^{2-7}$ For laterally luxated teeth with no occlusal interference, the preferred treatment is follow-up for spontaneous repositioning. In cases of minor occlusal interfer-

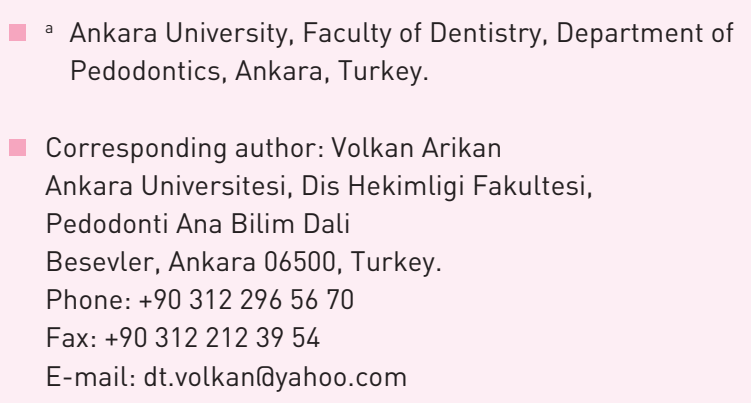

ence, slight grinding is recommended. When serious occlusal interference occurs, repositioning with pressure is recommended; however, if repositioning with pressure is impossible because of the time lapse between injury and application, then extraction is preferred. In the case reported here, instead of extraction, a laterally luxated primary central incisor with occlusal interference was repositioned, using a composite inclined plane.

\section{CASE REPORT}

A 4-year-old girl applied to our clinic 3 days after a traumatic injury with a complaint of pain and transposition of the left primary maxillary central incisor. Clinical and radiographical examination showed the tooth to be laterally luxated (Figures 1 and 2). Radiographically, neither the root nor the alveolar bone showed any sign of fracture. The crown was displaced in the palatinal direction, 
and the germ was judged to be safe. The tooth exhibited serious occlusal interference with the mandibular left primary incisor, and the child suffered from spontaneous pain. However, due to the length of time elapsed between the time of injury and the presentation at our clinic, the tooth could not be replaced in its original position in the alveolar socket.

The chosen treatment plan consisted of repositioning the tooth using a composite inclined plane, following the application of a root-canal treatment. The treatment options were explained to the parents, who gave their informed consent. The root canal treatment was performed using calcium hydroxide paste (Metapaste, Meta Biomed, Cheongju, Koreal, and the tooth was restored with compomer (Dyract AP, Dentsply International). Following restoration, the labial and incisal surfaces of the lower primary central incisors were etched with phosphoric acid for $40 \mathrm{~s}$, washed for $30 \mathrm{~s}$, and dried. Composite-resin restoration material (Grandio, VOCO, Cuxhaven, Germanyl was applied to the incisal surfaces to form a 3-4 $\mathrm{mm}$ plane, inclined at a $45^{\circ}$ to the longitudinal axes of the teeth. The only contact between the two arch-

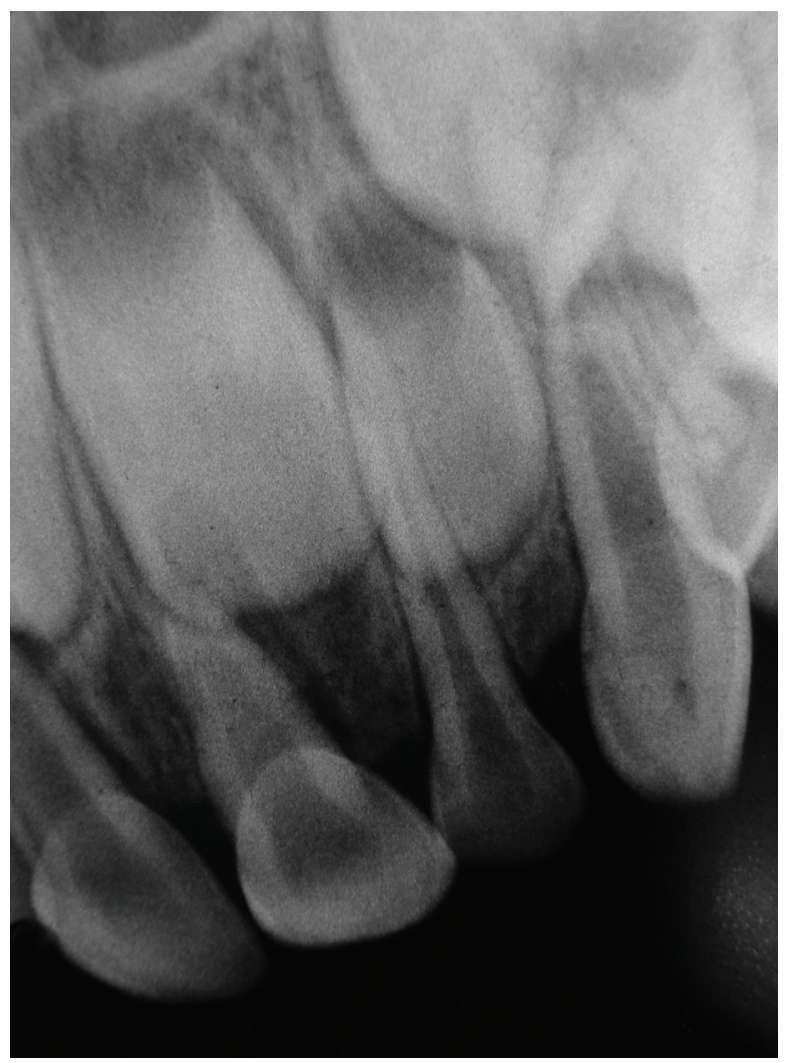

Figure 1. Preoperative radiograph of the laterally luxated tooth. es was at the incisal edge of the luxated tooth and the inclined plane (Figure 3).

By the end of the first week, the left maxillary central incisor had moved in the labial direction, but it had not yet repositioned completely. After two weeks of close follow-up, the tooth had returned to its original position, the inclined plane was removed, and the lower central incisors were polished with prophylaxis paste. During the follow-up period, the treated tooth was examined for percussion and palpation sensitivity, mobility, swelling, periapical radiolucency, and pathological root resorption. No clinical or radiographical pathology was observed. At the 1-year follow-up examination, the treatment was judged to be both clinically and radiographically successful (Figures 4 and 5). Follow-up is expected to continue until exfoliation of the tooth.

\section{DISCUSSION}

The recommended treatment for laterally luxated primary teeth with occlusal interference is repositioning with pressure; ${ }^{8}$ however, a delay between the time of injury and presentation for treatment may prevent repositioning. In such cases,

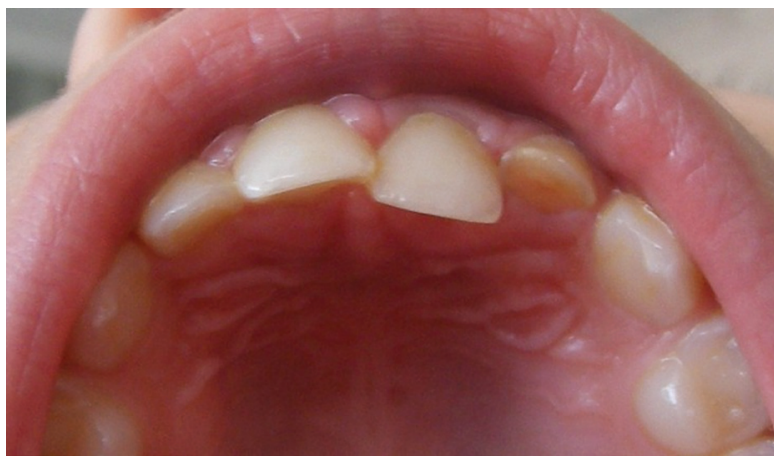

Figure 2. Intraoral view of the laterally luxated tooth showing the luxation in the palatinal direction.

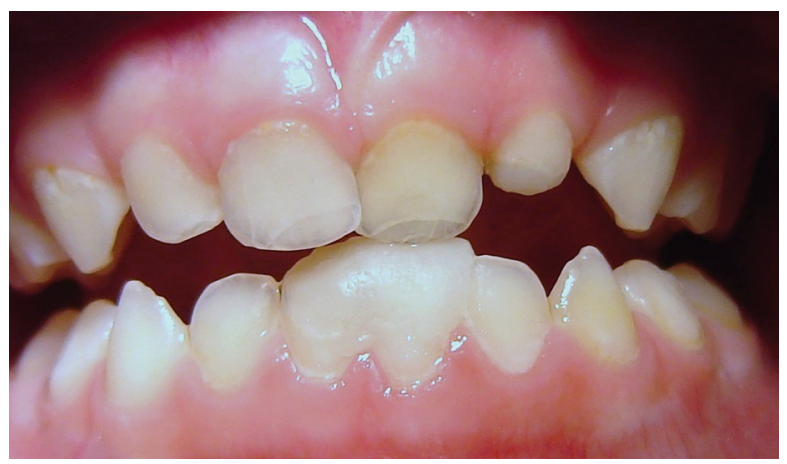

Figure 3. Clinical photograph showing the contact between the incisor and the inclined plane. 
grinding may correct the occlusal interference; however, if the interference cannot be resolved by grinding, then extraction of the tooth is required. Whereas the grinding procedure can harm the structure of a healthy tooth, the loss of an anterior tooth, especially in a young child, can lead to poor phonetics, the development of bad habits, and loss of function. In addition, poor esthetics due to tooth loss can cause psychological and social problems for children. ${ }^{1}$ In this case report, instead of extraction, an inclined plane constructed from composite resin was used to reposition a primary incisor with a crossbite caused by lateral luxation.

The literature describes a number of different methods for the correction of crossbite in primary and permanent teeth. One very simple method entails the use of a "bite stick"9-12 (i.e., a wooden tongue blade), which children are instructed to bite during their free time. However, used alone, this method has been reported to be unsuccessful because it depends on the cooperation of the patients and their parents. ${ }^{13}$

Another method for correcting an anterior crossbite is the use of a removable acrylic appliance, ${ }^{10,12,14}$ consisting of an acrylic plate that opens

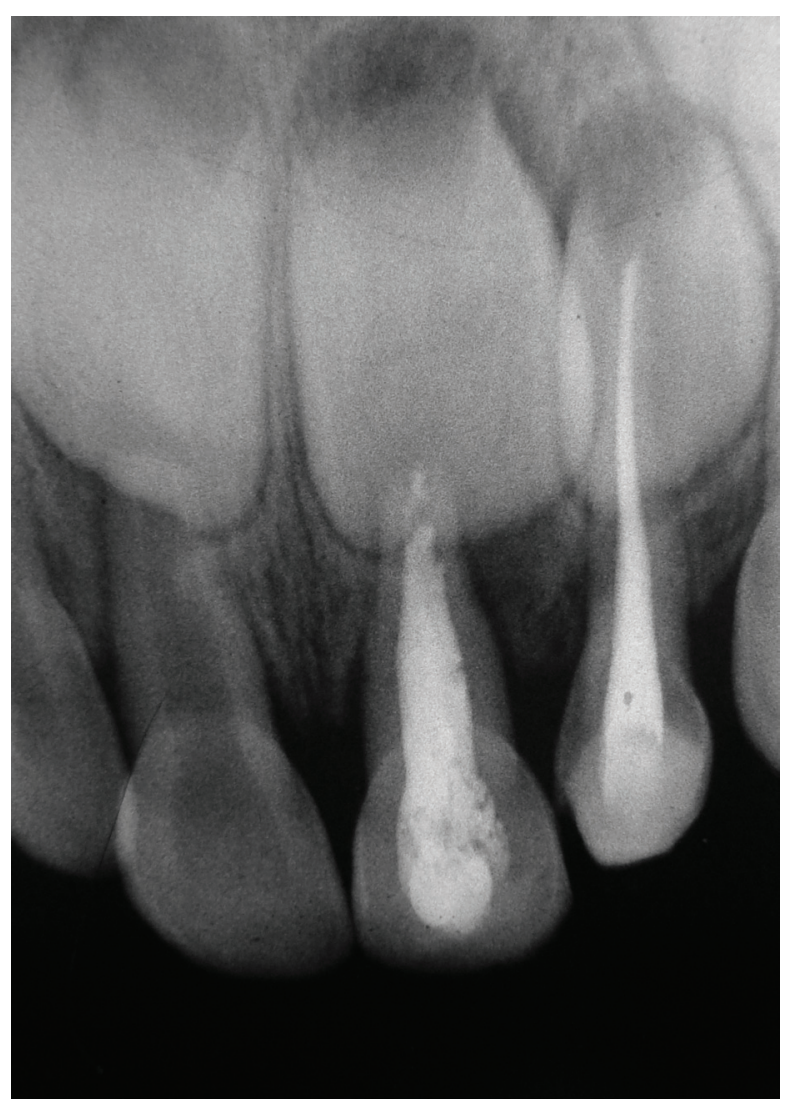

Figure 4. Radiograph of the tooth 1 year after the treatment showing no signs of pathologies. the posterior bite and a finger spring that tips the anterior teeth forward. However, like tongue blades, the success of acrylic appliances also depends on patient cooperation, which is difficult to achieve with younger children.

Numerous studies have reported the use of inclined planes for the correction of an anterior crossbite. By directing vertical bite forces forward, the inclined plane helps to tip the tooth in a labial direction. Various authors have reported different ways of forming fixed inclined planes, each with its own advantages and disadvantages. Reversed stainless steel crowns have been used successfully for this purpose, ${ }^{9-11,13,15,16}$ but considering their poor esthetics, they do not appear to be the best alternative for children. A lower inclined acrylic bite plane is another type of fixed inclined plane; however, it must be prepared in a laboratory, ${ }^{9,11,16}$ which results in an increase in both cost and number of appointments needed. Compositeresin inclined planes used to correct an anterior crossbite have been reported to be safe, quick and easy to apply, comfortable, and esthetically acceptable..$^{17,18}$ In the case reported here, a composite-resin inclined plane was used successfully to treat a laterally luxated primary tooth.

Although the treatment was successful in this case, clinicians should be aware of some possible risks posed by using this method to treat laterally luxated teeth in young children. It can be difficult to achieve follow-up cooperation from young children, who may not be capable of tolerating the posterior open-bite that occurs during the treatment period. Additionally, the use of force on a tooth that has already been injured may not be ap-

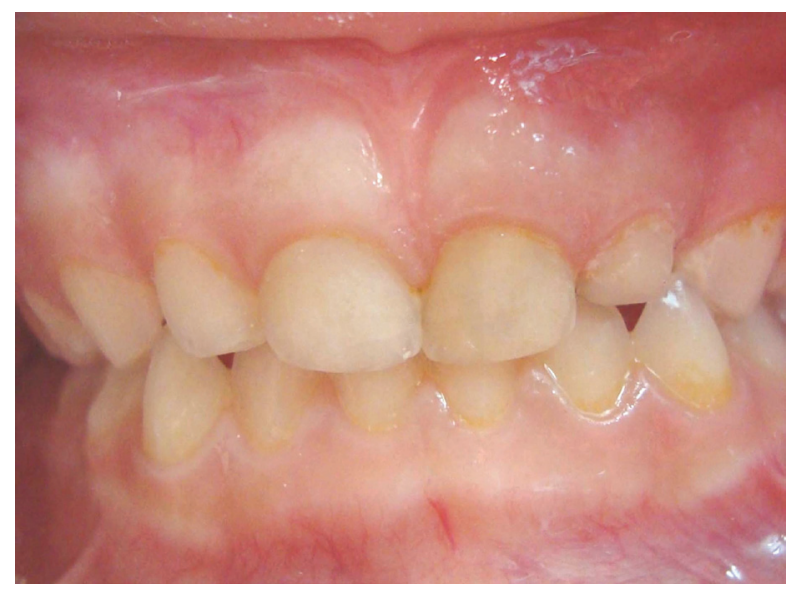

Figure 5. Clinical photograph of the tooth 1 year after the treatment. 
propriate. Because the guidelines recommend using appropriate pressure on laterally luxated teeth with occlusal interference to reposition them in the alveolar bone, ${ }^{8}$ and because the force applied by an inclined plane is limited, this method could provide a safe method for repositioning laterally luxated teeth after a root-canal treatment.

\section{CONCLUSIONS}

The use of a composite-resin inclined plane after a root-canal treatment, along with careful follow-up, can be an alternative to extraction for laterally luxated primary incisors with occlusal interference.

\section{REFERENCES}

1. Glendor $U$, Andersson L. Public health aspects of oral diseases and disorders: dental trauma. In: Pine C, Harris R, editors. Community oral health. London: Quintessence publishing; 2007, pp. 203-214.

2. Ngan $P$, Fields $H$. Orthodontic diagnosis and treatment planning in the primary dentition. ASDC J Dent Child 1995;62:25-33.

3. Cunha RF, Pugliesi DM, Mello Vieira AE. Oral trauma in Brazilian patients aged 0-3 years. Dent Traumatol 2001;17:210212.

4. Llarena del Rosario ME, Acosta AV, Garcia-Godoy F. Traumatic injuries to primary teeth in Mexico City children. Endod Dent Traumatol 1992;8:213-214.

5. Saroḡlu I, Sönmez H. The prevalence of traumatic injuries treated in the pedodontic clinic of Ankara University, Turkey, during 18 months. Dent Traumatol 2002;18:299-303.

6. Skaare AB, Jacobsen I. Primary tooth injuries in Norwegian children (1-8 years). Dent Traumatol 2005;21:315-319.

7. Oliviera LB, Marcenes W, Ardenghi TM, Sheiham A, Bönecker M. Traumatic dental injuries and associated factors among Brazilian preschool children. Dent Traumatol 2007;23:76-81.

8. Flores MT, Malmgren B, Andersson L, Andreasen JO, Bakland LK, Barnett F, Bourguignon C, DiAngelis A, Hicks L, Sigurdsson A, Trope M, Tsukiboshi M, von Arx T. Guidelines for the management of traumatic dental injuries. III. Primary teeth. Dent Traumatol 2007;23:196-202.

9. Valentine F, Howitt JW. Implications of early anterior crossbite correction. ASDC J Dent Child 1970;37:420-427.

10. Sim J. Minor tooth movement in children. eds. 2 St Louis, CV Mosby Company.1977: pp. 243-271.

11. Lee BD. Correction of crossbite. Dent Clin North Am 1978;22:647-668
12. Croll TP, Riesenberg RE. Anterior crossbite correction in the primary dentition using fixed inclined plane I. Quintessence Int 1988; 1:546-552.

13. Croll TP. Fixed inclined plane correction of anterior crossbite of the primary dentition. J Pedod 1984;9:84-97.

14. Jacobs SG. Teeth in crossbite: the role of removable appliances. Aust Dent J 1989;34:20-28.

15. Sexton T, Croll TP. Anterior crossbite correction in the primary dentition using stainless steel crowns. J Dent Child 1983;50:117-120.

16. Graber TM. Orthodontics-principles and practice.eds. 3. Philadelphia. W.B. Saunders Company 1972: pp. 673-675, 833-847.

17. Estreia F, Almerich J, Gascon F. Interceptive correction of anterior crossbite. J Dent Child 1991;15:157-159.

18. Sari S, Gokalp H, Aras S. Correction of anterior dental crossbite with composite as an inclined plane. Int J Paediatr Dent 2001;11:201-208. 